Research Paper

\title{
Anti-cancer therapeutic benefit of red guava extracts as a potential therapy in combination with doxorubicin or targeted therapy for triple-negative breast cancer cells
}

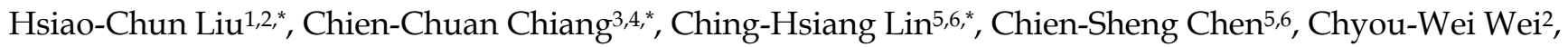



1. Department of Nursing, Taipei Tzu Chi Hospital, Buddhist Tzu Chi Medical Foundation, New Taipei 231, Taiwan

2. Department of Nutrition, Master Program of Biomedical Nutrition, Hungkuang University, Taichung 433, Taiwan

3. Graduate Institute of Biomedical Sciences, China Medical University, Taichung 404, Taiwan

4. enter for Molecular Medicine, China Medical University Hospital, Taichung 404, Taiwan

5. Department of Emergency Medicine, Taipei Tzu Chi Hospital, Buddhist Tzu Chi Medical Foundation, New Taipei 231, Taiwan

6. Department of Emergency Medicine, School of Medicine, Tzu Chi University, Hualien 970, Taiwan

7. Drug Development Center, China Medical University, Taichung 404, Taiwan

8. Department of Biotechnology, Asia University, Taichung 413, Taiwan

${ }^{*}$ Contributed equally

$\triangle$ Corresponding author: Graduate Institute of Biomedical Sciences, China Medical University, 6 Hsueh Shih Road, Taichung 404, Taiwan. E mail address: ylyu@mail.cmu.edu.tw (Y.-L. Yu); Department of Emergency Medicine, Taipei Tzu Chi Hospital, Buddhist Tzu Chi Medical Foundation, New Taipei 231, Taiwan. E-mail address: jtyiang@tzuchi.com.tw (G.-T. Yiang).

(C) The author(s). This is an open access article distributed under the terms of the Creative Commons Attribution License (https://creativecommons.org/licenses/by/4.0/). See http://ivyspring.com/terms for full terms and conditions.

Received: 2019.09.09; Accepted: 2020.03.25; Published: 2020.04.06

\begin{abstract}
Guava extracts purified from leaf and bark have many bio-active molecules with anti-cancer activities. In addition, lycopene-rich extracts obtained from red guava fruit can induce apoptosis in estrogen receptor-positive breast cancers. Triple-negative breast cancer (TNBC) lacks estrogen receptors, progesterone receptors and human epidermal growth factor receptor 2 (HER2) and, therefore, hormone therapy and targeted therapy are not used in the clinic. The purpose of this study was to determine whether red guava fruit extracts can affect the proliferation of TNBC cells. In this study, cell viability was determined by using the MTT assay. Apoptosis and necrosis were analyzed using flow cytometry. Cleaved caspase- 3 and PARP were analyzed by western blotting. We found that red guava extracts can, through caspase- 3 activation and PARP cleavage signaling, induce apoptotic and necrotic death in TNBC cells. Our results thus show the therapeutic benefit of red guava extracts as a potential cancer treatment for TNBC in combination with doxorubicin or targeted therapy.
\end{abstract}

Key words: Red guava, Triple-negative breast cancer, Apoptosis, Necrosis

\section{Introduction}

Many studies have demonstrated that guava extracts have anti-inflammatory, anti-microbial, anti-oxidative and anti-cancer activities [1-3]. These functions of guava extracts are related to numerous bio-active molecules such as beta-caryophyllene oxide, vitamins, tannins, phenolic compounds, flavonoids and triterpenoid acids [2,4-6]. Previous studies have demonstrated that guava extracts can inhibit cell growth in various cancers such as lung cancer, colorectal carcinoma, myeloid leukemia, squamous cell carcinoma, myeloma, cervical cancer and gastric cancer $[3,7,8]$. However, the mechanisms induced by guava extracts that result in anti-cancer activities remain unknown.

Breast cancer is the second major cause of death among cancers that are generally diagnosed in women $[9,10]$. Breast cancer commonly has invasive characteristics and a high rate of metastasis, which result in high morbidity and mortality [11,12]. Currently, chemotherapy, hormone therapy and targeted therapy are the most common breast cancer 
treatments [13,14]. About $15-20 \%$ of breast cancer occurrences are triple-negative breast cancer (TNBC) [15]. TNBC lacks estrogen receptors (ERs), progesterone receptors (PRs) and epidermal growth factor receptor 2 (HER2), and, therefore, chemotherapy, hormone therapy and targeted therapy are not useful for TNBC treatment [16-18]. Thus the development of a method for treating TNBC is important.

Some studies have suggested that guava extracts, most of which were purified from guava leaves or guava bark, are potential materials for breast cancer treatment $[5,19,20]$. Guava extracts are suggested to have estrogen-like activity, and, therefore, guava extracts are useful for treating ER-positive breast cancer cells, such as MCF-7 cells [19]. Although aqueous extracts of guava fruit may not display effective anti-cancer activity [21], lycopene-rich extracts from red guava fruit can induce apoptosis-like cell death among ER-positive breast cancer cells [22]. Thus different guava species have different bioactive components that result in different activities. However, whether lycopene or other bioactive molecules from red guava fruit have anti-cancer activities on TNBC cells remains to be studied.

Doxorubicin, a DNA topoisomerase II inhibitor, has been used as a chemical therapy for cancers, including breast cancer [23,24]. However, doxorubicin is not effective for TNBC treatment. Other agents may be used to enhance doxorubicin-induced anti-cancer activity on TNBC [25]. Tarceva (Erlotinib) and Iressa (Gefitinib), both of which are EGFR inhibitors, are used as targeted therapy for breast and other cancers $[26,27]$. Because EGFR is frequently overexpressed in TNBC, but up to now EGFR inhibitors are not useful drugs for TNBC treatment. To enhance the anti-cancer activity of tarceva and iressa on TNBC, combination therapy is required $[28,29]$. In this study, we show that extracts from red guava fruit can promote anti-cancer activities in iressa-, tarceva- and doxorubicin-treated TNBC.

\section{Materials and methods}

\section{Materials}

Red guavas were kindly provided by a farmer, Lin Chao Hsiung (A Fong guava farm, Houbi Dist., Tainan City 731, Taiwan). Doxorubicin, Erlotinib (Tarceva; Roche, Basel, Germany) and Gefitinib (Iressa; Astra Zeneca, London, England) were dissolved in dimethyl sulfoxide (DMSO) and the concentrations of drugs were referred to previous studies $[15,25,30]$. Doxorubicin was obtained from China Medical University Hospital. Antibodies against caspase-3 (cat no. 9662), caspase-8 (cat no. 9746), caspase-9 (cat no. 9502), PARP (cat no. 9542) and cleaved caspase-3 (cat no. 9664) were obtained from Cell Signaling Technology (Beverly, MA, USA). The MTT assay kit and antibodies against a-tubulin (cat no. T607) and $\beta$-actin (cat no. A2228) were purchased from Sigma (St. Louis, MO, USA). Amicon Ultra Filters $(\leq 30 \mathrm{kDa}$; No. UFC900324) were purchased from Millipore (Billerica, MA, USA). Fluorescein isothiocyanate-labeled annexin V (annexin V-FITC), propidium iodide (PI) and Western Lightning Plus-ECL enhanced chemiluminescent substrate were purchased from Perkin Elmer (EU, USA).

\section{Cell lines and cell culture}

The human mammary epithelial cell line MCF-10A and human TNBC cell lines MDA-MB-231 and MDA-MB-468 were purchased from American Type Culture Collection. These cells were maintained in a humidified atmosphere containing $5 \% \mathrm{CO}_{2}$ at $37^{\circ} \mathrm{C}$ and cultured in Dulbecco's modified Eagle's medium plus F12 (DMEM/F12 = 1:1) supplemented with $10 \%$ fetal bovine serum, penicillin (100 U OR IU OR UI/mL) and streptomycin $(100 \mu \mathrm{g} / \mathrm{mL}$; all from Sigma). In addition, insulin (10 $\mu \mathrm{g} / \mathrm{mL}$; Sigma) was used for MCF-10A cells.

\section{Guava extract preparation}

Guava extracts were prepared as described [1]. Briefly, extracts from the mature stage of the red guava fruit were used in this study. The fruits were cut and seed sections removed before the flesh was ground with a pure juice machine (NationalMJ-C85N) to prepare a crude juice without extra water. The crude juice was centrifuged at 4,000 $\times g$ (BECKMAN COULTER Allegra X-15®) for $30 \mathrm{~min}$, and the supernatant was collected (total extract). The lower molecular weight ( $\leq 30 \mathrm{kDa}$ ) extracts (LMW extracts) were obtained from total guava extracts centrifuged at $4^{\circ} \mathrm{C}, 4000 \times \mathrm{g}$ for $30 \mathrm{~min}$ in an Amicon Ultra Filter. Finally, total extracts and LMW extracts were filtered with a $0.22-\mu \mathrm{m}$ filter and stored at $-80^{\circ} \mathrm{C}$ until use. The protein concentration of total extracts and LMW extracts was $\sim 1.8 \mathrm{~g} / \mathrm{ml}$.

\section{Cell viability assay}

Cell viability was determined with the MTT assay kit. Cells were cultured in 96-well plates $\left(6 \times 10^{3}\right.$ cells/well). After the indicated treatments, control and experimental cells were incubated for $3 \mathrm{~h}$ at $37^{\circ} \mathrm{C}$ with components from the MTT assay kit. The absorbance of the reactive product was measured at $570 \mathrm{~nm}$ by using a Multiskan ${ }^{\mathrm{TM}}$ FC Microplate Photometer (Molecular Devices, Sunnyvale, CA, 
USA). Cell viability is indicated as a percentage corresponding to $\left(A_{570}\right.$ experimental group $) /\left(A_{570}\right.$ control group) $\times 100$.

\section{Cell cycle analysis}

Cell cycle analysis was conducted using fluorescence-activated cell sorting. Cells from control and experimental groups were washed with phosphate-buffered saline (PBS) and fixed with 70\% ethanol at $4^{\circ} \mathrm{C}$ for $1 \mathrm{~h}$. The fixed cells were washed with PBS for $5 \mathrm{~min}$ and then treated with $1 \mathrm{ml}$ PI solution containing $50 \mu \mathrm{g} / \mathrm{ml} \mathrm{PI}, 100 \mu \mathrm{g} / \mathrm{ml}$ RNase A and $0.1 \%$ Triton $\mathrm{X}-100$ for $30 \mathrm{~min}$ at $37^{\circ} \mathrm{C}$. The cells were then washed with PBS and analyzed by flow cytometry (Partec CyFlow ${ }^{\circledR}$ SL; SysmexPartec GmbH, Görlitz, Germany). The resulting data were analyzed with CellQuest software (Becton-Dickinson).

\section{Apoptosis and necrosis assay}

Apoptosis and necrosis were determined by annexin V-FITC/PI staining. Briefly, control and experimental cells were collected and washed with cold PBS buffer. Cells were resuspended in $100 \mu \mathrm{L}$ Annexin V/PI buffer and then treated with $5 \mu \mathrm{L}$ of annexin V-FITC and $1 \mu \mathrm{L}$ of PI for $15 \mathrm{~min}$ in the dark (at room temperature). Viable, apoptotic (annexin $\mathrm{V}^{+}$) and necrotic $\left(\mathrm{PI}^{+} /\right.$annexin $\left.\mathrm{V}^{-}\right)$cells were analyzed by flow cytometry and quantified with CellQuest software.

\section{Western blotting}

The cells were treated with RIPA buffer (EMD Millipore, Billerica, MA, USA) and centrifuged (16,000 $\times g$ at $4^{\circ} \mathrm{C}$ ) for $20 \mathrm{~min}$, and then cellular proteins were collected from the supernatant layer. Protein concentrations were determined with a Bradford protein assay kit (Bio-Rad, Hercules, CA, USA). Equal quantities $(20 \mu \mathrm{g})$ of protein were loaded onto an SDS-polyacrylamide gel and separated by electrophoresis. The proteins were transferred from the gel to PVDF membranes (EMD Millipore). The membranes were blocked with 5\% non-fat milk solution for $2 \mathrm{~h}$ at room temperature and were then washed with TBST buffer three times. The membranes were further incubated with primary antibodies at $4^{\circ} \mathrm{C}$ overnight. After being washed with TBST three times, the membranes were incubated with secondary antibodies for $1 \mathrm{~h}$ at room temperature. Finally, the membranes were treated with Western Lightning ${ }^{\circledR}$ Plus-ECL (Perkin Elmer, EU, USA), and immunolabeled proteins were observed using a Luminescence Image Analysis System (LAS-4000, FUJIFILM Electronic Materials Taiwan Co., Ltd., Tainan).

\section{Statistical analysis}

Data were collected from three independent experiments and are indicated as the mean \pm SD. Means were analyzed with the t-test method by using Microsoft

Excel (http:// microsoft-excel-2010.updatestar.com/zh-tw). A P-value $<0.05$ was considered statistically significant. ${ }^{*} \mathrm{P}<0.05,{ }^{* *} \mathrm{P}<0.01$.

\section{Results}

\section{Extracts from red guava fruit decrease cell viability in TNBC cells}

Two extract types from red guava fruit were analyzed: total extracts and smaller molecular weight ( $<30 \mathrm{kDa}$ ) extracts (LMW extracts). The two extract types were first incubated with normal breast cells (MCF-10A) and no extract type decreased the viability of MCF-10A cells (Fig. 1A). Total extracts and LMW extracts were also used to treat TNBC cells (MDA-MB-231 and MDA-MB-468) under the same conditions. Both extracts decrease the viability of the TNBC cells (Fig. 1B). Moreover, comparted with control group, the viability of MDA-MB-468 was significantly difference in guava extract-treated group with a P-value $<0.05$.
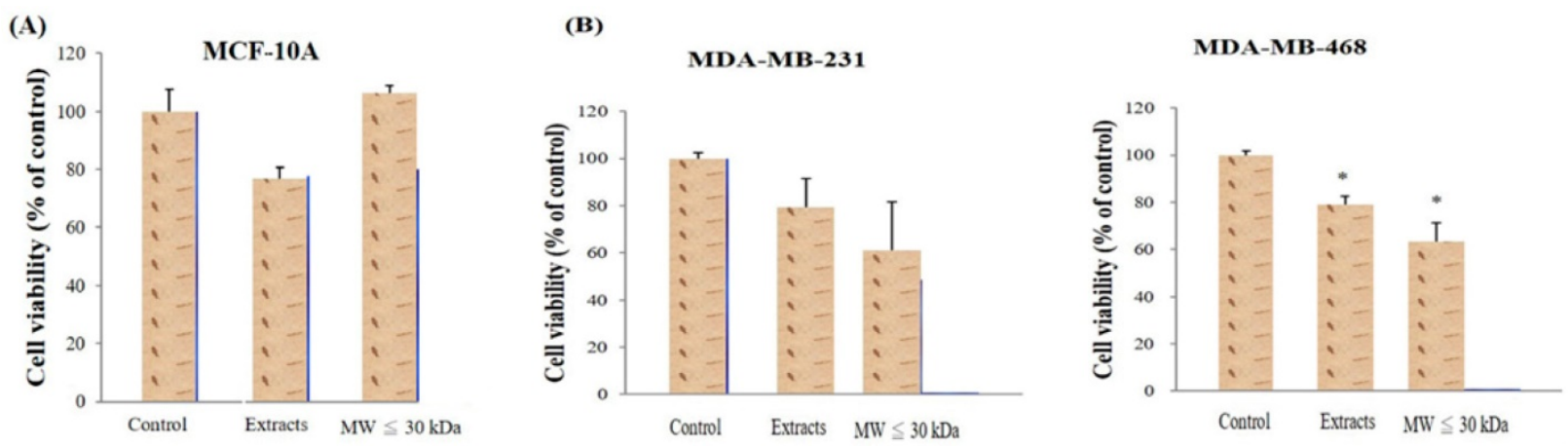

Figure 1. Determination of red guava extract effects on cell viability. (A) Human mammary epithelial cells (MCF-10A) were treated with no guava extract (control), $10 \%$ total extract (extracts) or $10 \%$ LMW extracts (MW $\leq 30 \mathrm{kDa}$ ) for $72 \mathrm{~h}$ at $37^{\circ} \mathrm{C}$. (B) TNBC cells (MDA-MB-231 and MDA-MB-468) were treated with no guava extract, $10 \%$ total extract or $10 \% \mathrm{LMW}$ extract as in A. The 72 -h cell viability was measured by MTT analysis. Values are expressed as the mean \pm standard deviation from three independent experiments. $* \mathrm{P}<0.05$. 
(A)
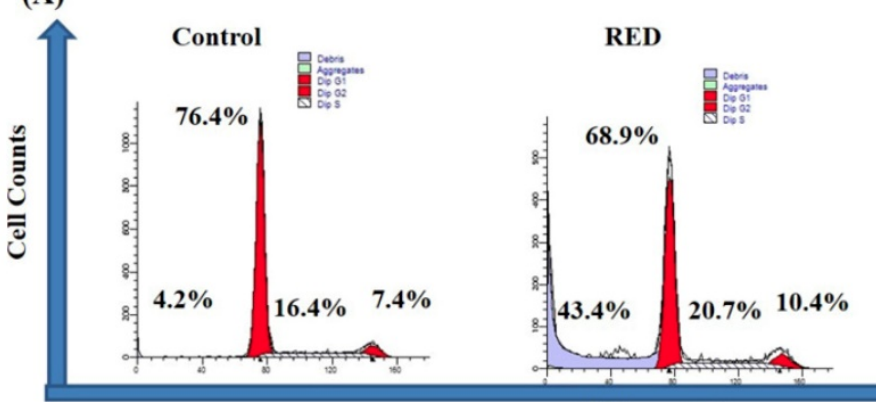

$\mathbf{M W} \leqq 30 \mathrm{kDa}$

MDA-MB-231

DNA content

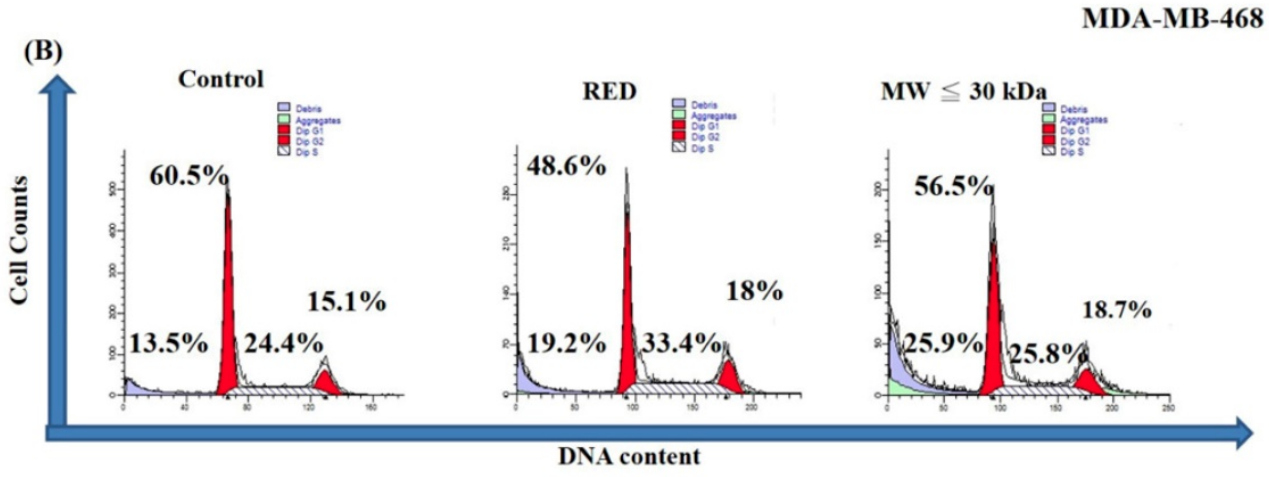

Figure 2. Cell cycle analysis of TNBC cells treated with red guava extracts. (A) MDA-MB231 and (B) MDA-MB-468 cells were treated with no guava extract (control), $10 \%$ total extract (RED) or $10 \% \mathrm{LMW}$ extract $(\mathrm{MW} \leq 30 \mathrm{kDa})$. The cells were fixed with ethanol and stained with PI. The cell cycle after extract exposure for $72 \mathrm{~h}$ was analyzed by flow cytometry.

\section{Extracts from red guava fruit induce cell cytotoxicity in MDA-MB-231 and MDA-MB-468 cells via different cell death pathways}

A cell cycle analysis was carried out on TNBC cells treated with total extracts and LMW extracts for 72h. As shown in Figure 2A, the sub-G1 percentages of MDA-MB-231 cells were $4.2 \%, 43.4 \%$ and $34.1 \%$ in the control, total extract and LMW extract groups, respectively. On the other hand, the sub-G1 percentage of MDA-MB-468 was increased with guava extracts treatment with sub-G1 percentages of $13.5 \%, 19.2 \%$ and $25.9 \%$ in the control, total extract and LMW extract groups, respectively (Fig. 2B). Thus both the total extracts and LMW extracts from red guava fruit increased the sub-G1 percentage of TNBC cells. That is, red guava extracts were able to induce cell cytotoxicity in TNBC cells. Cell death is generally classified as apoptotic cell death or necrotic cell death. We used an annexin V/PI assay to determine the occurrence of apoptotic and necrotic cell death in these cells. As shown in Figure 3A, MDA-MB-231 cells that were treated with total extract $(31.4 \%$ necrosis and $9.4 \%$ apoptosis) or LMW extract (24.4\% necrosis and $7.6 \%$ apoptosis) had higher necrosis and apoptosis percentages as compared with control cells ( $1.7 \%$ necrosis and $0.3 \%$ apoptosis). Thus total extract and LMW extract induced a higher percentage of dead cells as a result of the necrotic death pathway rather than the apoptotic death pathway in MDA-MB-231cells. In contrast, as shown in Figure 3B, MDA-MB-468 cells that were treated with total extract (7.0\% necrosis and $43.9 \%$ apoptosis) or LMW extract (5.2\% necrosis and $65.5 \%$ apoptosis) had only a higher apoptosis percentage as compared with control cells (7.6\% necrosis and $0.4 \%$ apoptosis). Thus total extract and LMW extract induced apoptosis in MDA-MB-468 cells.

\section{Extracts from red guava fruit induce cell death in MDA-MB-231 and MDA-MB-468 cells via PARP cleavage and caspase- 3 activation}

PARP and caspase- 3 activity were assessed in TNBC cells treated with total extract and LMW extract. Based on western blotting, cleavage of PARP was increased in MDA-MB-231 and MDA-MB-468 cells treated with both extract types (Fig. 4). Caspase-3 is the upstream signal of PARP, and, therefore, caspase- 3 activation was also analyzed. Cleavage of caspase- 3 was increased in the total extract and LMW extract groups (Fig. 4). These data suggested that extracts from red guava fruit activate the caspase-3/PARP signaling pathway to induce cytotoxicity in TNBC cells. 


\section{Extracts from red guava fruit promote chemotherapy-induced and targeted therapy-induced anti-cancer activities}

TNBCs lack the ER, PR and HER2, and, therefore, many clinical therapies are not effective for the treatment of TNBCs. Doxorubicin, a DNA topoisomerase II inhibitor, is used as a chemotherapy for many cancers including TNBCs. To confirm that doxorubicin is broadly effective against TNBC cells, we treated MDA-MB-231 and MDA-MB-468 cells with doxorubicin for 72h. Doxorubicin inhibited MDA-MB-231 cells; however, doxorubicin was not toxic to MDA-MB-468 cells (Fig. 5A). When extracts from red guava fruit (total extracts group and LMW extracts) were combined with doxorubicin treatment, the anti-cancer activities were significantly increased in MDA-MB-231 and MDA-MB-468 cells (Fig. 5A). Tarceva and Iressa both of which are EGFR inhibitors, are used as clinical targeted therapies for breast cancer. In our study, neither Tarceva nor Iressa effectively inhibited MDA-MB-231 or MDA-MB-468 cells (Fig. 5B and C). However, extracts from red guava fruit (total extracts group and LMW extracts) when combined with Tarceva or Iressa significantly increased their anti-cancer activities in MDA-MB-231 and MDA-MB-468 cells (Fig. 5B and C). Taken together, our findings suggested that extracts from red guava fruit could promote chemotherapy- and targeted therapy-induced anti-cancer activities.

\section{Discussion}

Many studies have demonstrated that guava extracts have anti-cancer activities on various cancers including lung cancer, colorectal carcinoma, myeloid leukemia, squamous cell carcinoma, myeloma, cervical cancer, gastric cancer and breast cancer $[3,7,8,19]$. However, whether guava extracts can inhibit TNBC growth had not been examined. Here we have shown that extracts from red guava fruit can induce cell death in TNBC cells. Most studies have shown that guava extracts induce large amounts of apoptotic death in various cancer cells $[7,22,31]$. Our study, in contrast, found that red guava extracts induce apoptotic and necrotic cell death in TNBC. Specifically, red guava extracts induced mainly necrotic cell death in MDA-MB-231 cells (more metastasis ability than MDA-MB-468), but they induced apoptotic cell death in MDA-MB-468 cells. Therefore, we suggest that red guava extract can lead to distinct activation of cell death pathways in different types of TNBC cells may dependent on their malignancy.

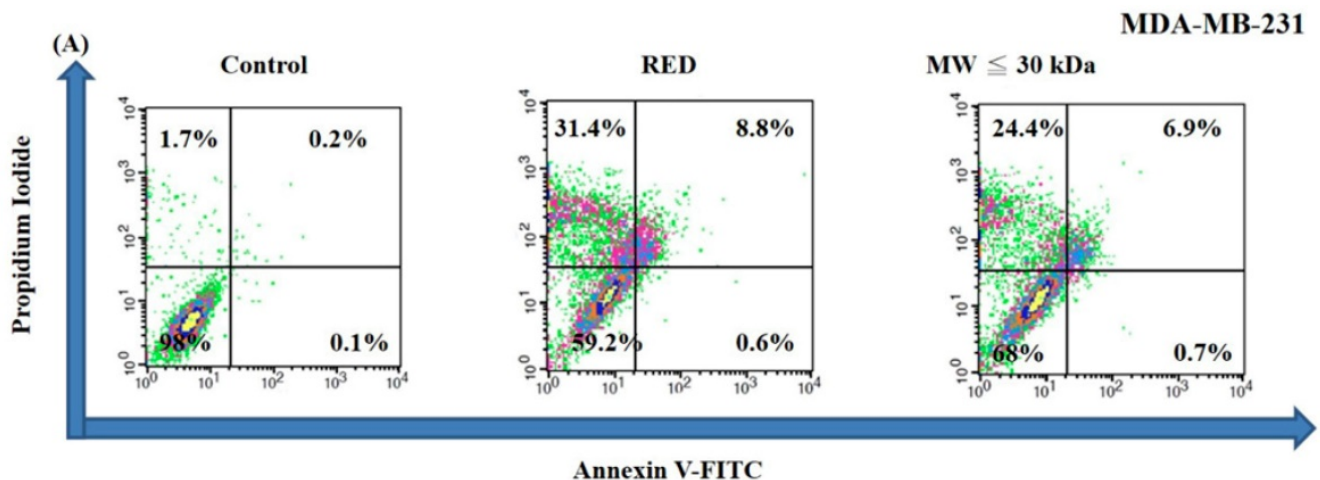

Annexin V-FITC
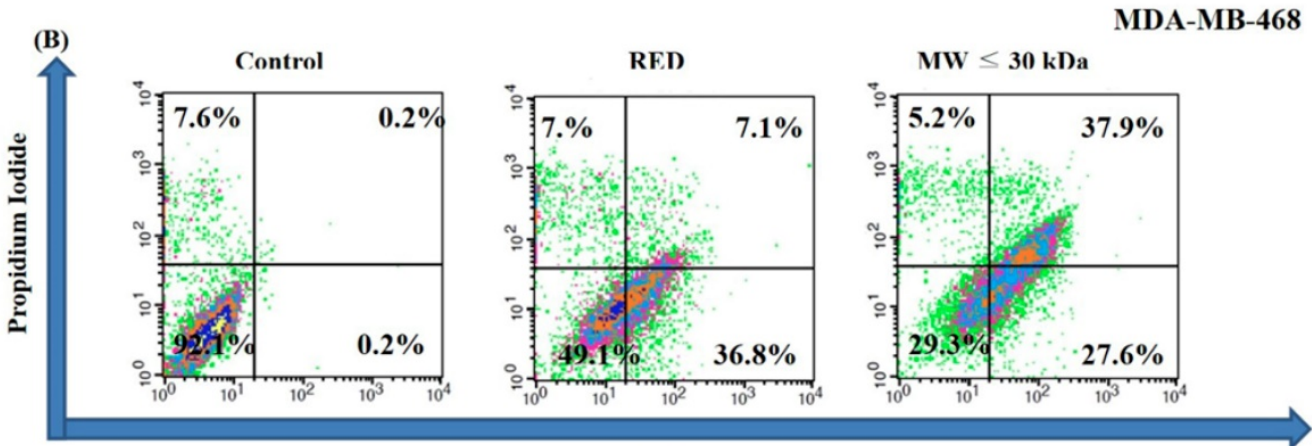

Annexin V-FITC

Figure 3. Apoptotic and necrotic cell death analysis in TNBC cells treated with red guava extracts. (A) MDA-MB231 and (B) MDA-MB-468 cells were treated with no guava extract (control), $10 \%$ total extract (RED) or $10 \% \mathrm{LMW}$ extracts (MW $\leq 30 \mathrm{kDa}$ ). After a treatment period of $72 \mathrm{~h}$, the cells were stained with annexin $\mathrm{V}-\mathrm{FITC}$ and PI and analyzed using flow cytometry. 


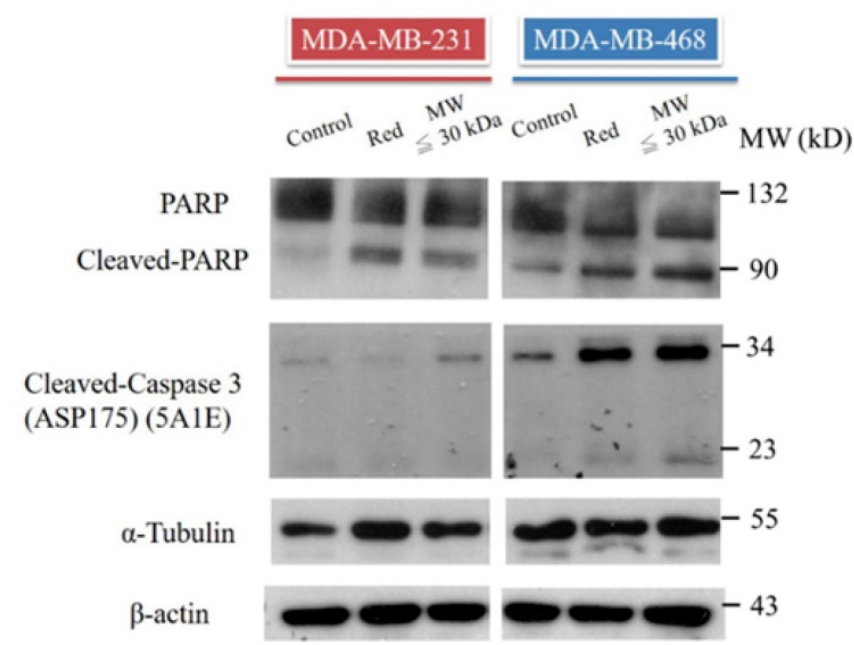

Figure 4. PARP, cleaved PARP and cleaved caspase-3 analysis in TNBC cells treated with red guava extracts. The protein levels of PARP, cleaved PARP and cleaved caspase- 3 were assayed by western blotting. Cells were treated with no guava extract (control), $10 \%$ total extract (RED) or $10 \%$ LMW extract (MW $\leq 30 \mathrm{kDa}$ ). Proteins were analyzed after $72 \mathrm{~h}$ of treatment. The protein levels of tubulin and actin were used as loading controls.
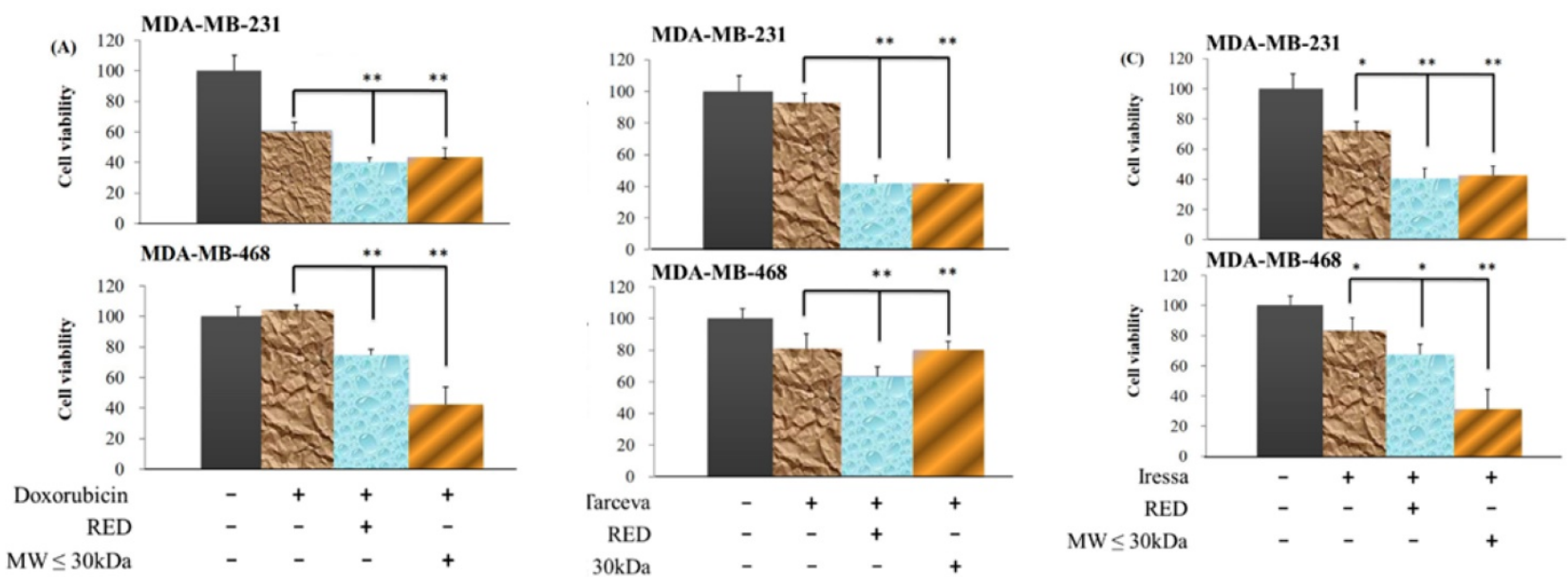

Figure 5. Cell viability of TNBC cells treated with guava extracts plus clinical anti-cancer drugs. (A) Cells were treated with $0 \mathrm{nM}$ doxorubicin (Control; column 1), $17 \mathrm{nM}$ doxorubicin (column 2), $17 \mathrm{nM}$ doxorubicin plus $10 \%$ total extracts (RED; column 3 ) or $17 \mathrm{nM}$ doxorubicin plus $10 \% \mathrm{LMW}$ extracts (MW $\leq 30 \mathrm{kDa}$; column 4). (B) Cells were treated with $0 \mu \mathrm{M}$ tarceva (column 1), $1 \mu \mathrm{M}$ tarceva (column 2), $1 \mu \mathrm{M}$ tarceva plus $10 \%$ total extracts (column 3 ) or $1 \mu \mathrm{M}$ tarceva plus $10 \% \mathrm{LMW}$ extracts (column 4 ). (C) Cells were treated with $0 \mu \mathrm{M}$ iressa (column 1), $1 \mu \mathrm{M}$ iressa (column 2 ), $1 \mu \mathrm{M}$ iressa plus $10 \%$ total extracts (column 3 ) or $1 \mu \mathrm{M}$ iressa plus $10 \% \mathrm{LMW}$ extracts (column 4 ). The 72 -h cell viability was measured by the MTT method. Values are expressed as the mean \pm standard deviation from three independent experiments. $* P<0.05, * * P<0.01$.

A previous study showed that extracts purified from guava fruit do not have anti-cancer activity in breast cancer cells [21]. However, extracts obtained from lycopene-rich red guava fruit can inhibit ER-positive breast cancer growth [22]. Here we also found that extracts purified from red guava fruit can inhibit TNBC growth, with LMW extracts and total extracts having similar cytotoxic effects on these cells. Lycopene is $<30 \mathrm{kDa}$, and thus the LMW extracts in this study likely contained lycopene molecules. Previous studies have demonstrated that lycopene has anti-cancer activities [32-34]. Based on the experimental results from our study and previous studies, we believe that lycopene is one of the important molecules in red guava fruit with respect to anti-cancer effects on TNBC cells.

Combination treatment of etoposide and doxorubicin can enhance cytotoxicity in TNBCs through the TRAIL-DR5 axis [25]. In addition, TRAIL signals can increase NF-kB activity [35], and guava extracts can regulate NF-kB activity [3]. Our data showed that red guava fruit extracts can promote doxorubicin-induced cytotoxicity in TNBC cells, but whether red guava extracts enhance this cytotoxicity via TRAIL/NF-kB signaling remains to be studied.

In support of another possible signaling pathway, combination treatment with EGFR inhibitors and PI3K/AKT inhibitors has a synergistic effect on TNBC [29]. Recently, a study reported that guava extracts can activate PI3K and AKT [36]. In our analysis, red guava extracts enhanced the cytotoxicity of EGFR inhibitors (tarceva and iressa) in TNBC cells. Therefore, we suggest that the PI3K/AKT pathway may play an important role in TNBC treatment.

Taken together, our study demonstrated that red guava extracts display anti-cancer activities in TNBC 
cells through apoptotic or necrotic cell death pathways and that red guava extracts promote doxorubicin-, tarceva- and iressa-induced cytotoxicity in TNBC cells.

\section{Acknowledgements}

Guava fruits were kindly provided by $\mathrm{Mr}$. Chao-Hsiung Lin from a fong guava farm, Houbi Dist., Tainan City, Taiwan. This study was supported by grants from the Ministry of Science and Technology, Taiwan (MOST106-2320-B-039-051-MY3; MOST107-2320-B-039-004); the Ministry of Health and Welfare, Taiwan (MOHW107-TDU-B-212-112-015); the China Medical University and Hospital, Taiwan (CMU105-TC-01; CMU108-MF-01; DMR-108-BC-4; DMR-108-BC-10; DMR-109-133) and the Taipei Tzu Chi Hospital, Taiwan (TCRD-TPE-108-23; TCRD-TPE-107-33; TCRD-TPE-107-34; TCRD-TPE106-36), and the work was financially supported by the "Drug Development Center, China Medical University" from The Featured Areas Research Center Program within the framework of the Higher Education Sprout Project by the Ministry of Education (MOE) in Taiwan. The manuscript has been edited by an International Bioscience Consultants (www.biomeditor.com; No. 18681).

\section{Competing Interests}

The authors have declared that no competing interest exists.

\section{References}

1. Wu TK, Liu HC, Lin SY, Yu YL, Wei CW. Extracts from guava fruit protect renal tubular endothelial cells against acetaminopheninduced cytotoxicity. Mol Med Rep. 2018; 17: 5544-51.

2. Ravi K, Divyashree P. Psidium guajava: A review on its potential as an adjunct in treating periodontal disease. Pharmacogn Rev. 2014; 8: 96-100.

3. Ashraf A, Sarfraz RA, Rashid MA, Mahmood A, Shahid M, Noor N. Chemical composition, antioxidant, antitumor, anticancer and cytotoxic effects of Psidium guajava leaf extracts. Pharm Biol. 2016; 54: 1971-81.

4. Shao M, Wang Y, Huang XJ, Fan CL, Zhang QW, Zhang XQ, et al. Four new triterpenoids from the leaves of Psidium guajava. J Asian Nat Prod Res. 2012; 14: 348-54.

5. Park KR, Nam D, Yun HM, Lee SG, Jang HJ, Sethi G, et al. beta-Caryophyllene oxide inhibits growth and induces apoptosis through the suppression of PI3K/AKT/mTOR/S6K1 pathways and ROS-mediated MAPKs activation. Cancer Lett. 2011; 312: 178-88.

6. Chang LC, Yu YL. Dietary components as epigenetic-regulating agents against cancer. Biomedicine (Taipei). 2016; 6: 2.

7. Qin XJ, Yu Q, Yan H, Khan A, Feng MY, Li PP, et al. Meroterpenoids with Antitumor Activities from Guava (Psidium guajava). J Agric Food Chem. 2017; 65: 4993-9.

8. Feng $\mathrm{XH}$, Wang $\mathrm{ZH}$, Meng DL, Li X. Cytotoxic and antioxidant constituents from the leaves of Psidium guajava. Bioorg Med Chem Lett. 2015; 25: 2193-8.

9. Bray F, Ferlay J, Soerjomataram I, Siegel RL, Torre LA, Jemal A. Global cancer statistics 2018: GLOBOCAN estimates of incidence and mortality worldwide for 36 cancers in 185 countries. CA Cancer J Clin. 2018; 68: 394-424.

10. DeSantis CE, Ma J, Goding Sauer A, Newman LA, Jemal A. Breast cancer statistics, 2017, racial disparity in mortality by state. CA Cancer J Clin. 2017; 67: 439-48.

11. Acevedo-Diaz A, Ortiz-Soto G, Suarez-Arroyo IJ, Zayas-Santiago A, Martinez Montemayor MM. Ganoderma lucidum Extract Reduces the
Motility of Breast Cancer Cells Mediated by the RAC(-)Lamellipodin Axis. Nutrients. 2019; 11.

12. Parvin T, Das C, Choudhury M, Chattopadhyay BK, Mukhopadhyay M. Prognostic Utility of Cyclin D1 in Invasive Breast Carcinoma. Indian J Surg Oncol. 2019; 10: 167-73.

13. Diaby V, Tawk R, Sanogo V, Xiao H, Montero AJ. A review of systematic reviews of the cost-effectiveness of hormone therapy, chemotherapy, and targeted therapy for breast cancer. Breast Cancer Res Treat. 2015; 151: 27-40.

14. Hou G, Qian J, Xu W, Sun T, Wang J, Wang Y, et al. Multifunctional PEG-b-polypeptide-decorated gold nanorod for targeted combined chemo-photothermal therapy of breast cancer. Colloids Surf B Biointerfaces. 2019; 181: 602-11.

15. Yu YL, Chou RH, Liang JH, Chang WJ, Su KJ, Tseng YJ, et al. Targeting the EGFR/PCNA signaling suppresses tumor growth of triple-negative breast cancer cells with cell-penetrating PCNA peptides. PLoS One. 2013; 8: e61362.

16. Ojo D, Wei F, Liu Y, Wang E, Zhang H, Lin X, et al. Factors Promoting Tamoxifen Resistance in Breast Cancer via Stimulating Breast Cancer Stem Cell Expansion. Curr Med Chem. 2015; 22: 2360-74.

17. Lumachi F, Chiara GB, Foltran L, Basso SM. Proteomics as a Guide for Personalized Adjuvant Chemotherapy in Patients with Early Breast Cancer. Cancer Genomics Proteomics. 2015; 12: 385-90.

18. Wu CW, Liu HC, Yu YL, Hung YT, Wei CW, Yiang GT. Combined treatment with vitamin $\mathrm{C}$ and methotrexate inhibits triple-negative breast cancer cell growth by increasing $\mathrm{H} 2 \mathrm{O} 2$ accumulation and activating caspase-3 and p38 pathways. Oncol Rep. 2017; 37: 2177-84.

19. Rizzo LY, Longato GB, Ruiz AL, Tinti SV, Possenti A, Vendramini-Costa $\mathrm{DB}$, et al. In vitro, in vivo and in silico analysis of the anticancer and estrogen-like activity of guava leaf extracts. Curr Med Chem. 2014; 21: 2322-30.

20. Kaileh M, Vanden Berghe W, Boone E, Essawi T, Haegeman G. Screening of indigenous Palestinian medicinal plants for potential anti-inflammatory and cytotoxic activity. J Ethnopharmacol. 2007; 113: 510-6.

21. Garcia-Solis P, Yahia EM, Morales-Tlalpan V, Diaz-Munoz M. Screening of antiproliferative effect of aqueous extracts of plant foods consumed in Mexico on the breast cancer cell line MCF-7. Int J Food Sci Nutr. 2009; 60 Suppl 6: 32-46.

22. Dos Santos RC, Ombredane AS, Souza JMT, Vasconcelos AG, Placido A, Amorim A, et al. Lycopene-rich extract from red guava (Psidium guajava L.) displays cytotoxic effect against human breast adenocarcinoma cell line MCF-7 via an apoptotic-like pathway. Food Res Int. 2018; 105: 184-96.

23. Zhu Y, Shi YJ, Zhao YL, Zhu P. [Topoisomerase inhibitor upregulates MICA/B expression in breast cancer cells through ATM/ATR and NF-kappaB pathway]. Beijing Da Xue Xue Bao Yi Xue Ban. 2018; 50: 318-25.

24. Damiani RM, Moura DJ, Viau CM, Caceres RA, Henriques JAP, Saffi J. Pathways of cardiac toxicity: comparison between chemotherapeutic drugs doxorubicin and mitoxantrone. Arch Toxicol. 2016; 90: 2063-76.

25. Das S, Tripathi N, Siddharth S, Nayak A, Nayak D, Sethy C, et al. Etoposide and doxorubicin enhance the sensitivity of triple negative breast cancers through modulation of TRAIL-DR5 axis. Apoptosis. 2017; 22: $1205-24$

26. Su CM, Chang TY, Hsu HP, Lai HH, Li JN, Lyu YJ, et al. A novel application of E1A in combination therapy with EGFR-TKI treatment in breast cancer. Oncotarget. 2016; 7: 63924-36.

27. Knox AJ, Scaling AL, Pinto MP, Bliesner BS, Haughian JM, Abdel-Hafiz $\mathrm{HA}$, et al. Modeling luminal breast cancer heterogeneity: combination therapy to suppress a hormone receptor-negative, cytokeratin 5-positive subpopulation in luminal disease. Breast Cancer Res. 2014; 16: 418.

28. El Guerrab A, Bamdad M, Kwiatkowski F, Bignon YJ, Penault-Llorca F, Aubel C. Anti-EGFR monoclonal antibodies and EGFR tyrosine kinase inhibitors as combination therapy for triple-negative breast cancer. Oncotarget. 2016; 7: 73618-37.

29. Yi YW, Hong W, Kang HJ, Kim HJ, Zhao W, Wang A, et al. Inhibition of the PI3K/AKT pathway potentiates cytotoxicity of EGFR kinase inhibitors in triple-negative breast cancer cells. J Cell Mol Med. 2013; 17: 648-56

30. Su KJ, Yu YL. Downregulation of SHIP2 by Hepatitis B Virus X Promotes the Metastasis and Chemoresistance of Hepatocellular Carcinoma through SKP2. Cancers (Basel). 2019; 11.

31. Bontempo P, Doto A, Miceli M, Mita L, Benedetti R, Nebbioso A, et al. Psidium guajava L. anti-neoplastic effects: induction of apoptosis and cell differentiation. Cell Prolif. 2012; 45: 22-31.

32. Takeshima $M$, Ono $M$, Higuchi $T$, Chen $C$, Hara $T$, Nakano $S$. Anti-proliferative and apoptosis-inducing activity of lycopene against 
three subtypes of human breast cancer cell lines. Cancer Sci. 2014; 105: 252-7.

33. Peng SJ, Li J, Zhou Y, Tuo M, Qin XX, Yu Q, et al. In vitro effects and mechanisms of lycopene in MCF-7 human breast cancer cells. Genet Mol Res. 2017; 16.

34. Assar EA, Vidalle MC, Chopra M, Hafizi S. Lycopene acts through inhibition of IkappaB kinase to suppress NF-kappaB signaling in human prostate and breast cancer cells. Tumour Biol. 2016; 37: 9375-85.

35. Sundaram K, Sambandam Y, Balasubramanian S, Pillai B, Voelkel-Johnson C, Ries WL, et al. STAT-6 mediates TRAIL induced RANK ligand expression in stromal/preosteoblast cells. Bone. 2015; 71: 137-44.

36. Vinayagam R, Jayachandran M, Chung SSM, Xu B. Guava leaf inhibits hepatic gluconeogenesis and increases glycogen synthesis via AMPK/ACC signaling pathways in streptozotocin-induced diabetic rats. Biomed Pharmacother. 2018; 103: 1012-7. 